\title{
El Atlántico en la historia y la leyenda
}

\author{
Antonio Antelo lglesias *
}

\section{EL MUNDO ANTIGUO}

Desde la Edad de Bronce, en Europa (III y II milenios a. Ch.), las costas atlánticas del Continente fueron visitadas por audaces navegantes, ya meridionales, de la Península Ibérica y acaso egeos, ya nórdicos, de las Islas Británicas tanto como de Escandinavia ${ }^{1}$. Merced a los emprendedores púnicos, que desde la batalla de Alalía (535 a. de J.C.) habian cerrado el estrecho de Gibraltar al comercio helénico, reservándose el monopolio de las rutas oceánicas al $\mathrm{N}$ y al $\mathrm{S}$ (estaño, ámbar, púrpura, bancos pesqueros, etc.), el mundio mediterráneo entró así - representado por una potencia semítica - en contacto con el Atlántico. Los fenicios y, antes de la hegemonía cartaginesa, los griegos focenses desde el siglo VII, estaban familiarizados con el SO de la península (Tartesos) y el NO africano; los primeros, incluso circunnavegaron África en tiempo del faraón Nekao (609593 a. de J.C.), mientras que los segundos (Periplo Massaliota, del siglo vi a. de J.C.) conocían el tráfico de Tartessos con las islas del estaño y parecían asimismo informados sobre algunos archipiélagos atlánticos ${ }^{2}$. El opulento reino de Ofir o Tierra de Oro atraía también a los marinos fenicios: su búsqueda originó expediciones diversas porque se ubicaba en distintos países, ya de Asia (SO de Arabia, reino de Saba), ya del África Sudoriental (Zimbadwe) u Occidental (Benin, Costa de Oro,...) ${ }^{3}$.

* Profesor Emérito de Historia Medieval. UNED.

Cf. Gordon ChiLde, V., The Prehistory of European Society. Harmondsworth 1958, págs. 116-23, 144-49 y 162-73 (A penguin Book, A415). CLARK, G.-PIGGOTT, S., Prehistoric Societies. Nueva York 1968, págs. 288-96, 301-2 y 309-13.

2 Los textos clásicos, comentados, se hallan en: García y Bellido, A., La Península lbérica en los comienzos de su historia, n. ed. Madrid 1985, caps. IV-Vl. Reproducción facsimilar de la ed. de 1953, con una semblanza del autor por Blanco Freijeiro, A. (Págs. 05-10).

${ }_{3}$ Para las referencias a Hiram y Salomón, cf. I Reyes, IX, 26, 28 y X, 11-12 y 22. Vid. también ThÉvenIN, R., Les pays légendaires devant la science, 2e éd. Paris 1949, págs. 24-40. 
Acerca de tales exploraciones antiguas son importantes los periplos de Hannón e Himilcón, ambos cartagineses (ca. 500-450 a. de J.C.), y el famoso viaje - permitido inexplicablemente por los púnicos- del marsellés Pytheas, en la segunda mitad del siglo IV.

Según Plinio "el Viejo», "en tiempos del florecimiento de la potencia de Carthago, Hanno navegó desde Gades (Cádiz) hasta los confines de Arabia, dando por escrito la historia de esta navegación. En el mismo tiempo Himilco fue comisionado para reconocer las partes externas de Europa» ${ }^{4}$. Del primero existe una transcripción bizantina (siglo x, Codex Heidelbergensis 398), que relata su llegada al Camerún y a la bahía de Biafra, desde donde regresó por falta de vituallas. No obstante, fundó una colonia o enclave, Cerne, cuya localización es muy imprecisa. En todo caso, el pasaje de Plinio no significa que Hannón hubiese alcanzado el $S$ del continente, verdadera terra incognita para el hombre antiguo, y, desde allí, la península arábiga. «En algunos meses estivales de un año próximo al 525 a. de J. C. -dice bien B. Landström-, exploró una extensión costera que los navegantes portugueses, casi 2000 años más tarde, emplearían 56 años en descubrir ${ }^{5}$.

A su vez, Himilcón, que se aventuró hasta el mar del norte, en las tierras del estaño, propagaría interesadamente noticias falsas o exageradas sobre los tremendos peligros que acechaban allí a los navegantes, contribuyendo de este modo al surgimiento de un Mare Tenebrosum, cuyos terrores agobiarían al Occidente hasta el siglo $\mathrm{xv}^{6}$. Fue entonces, en rigor, cuando las Columnas de Hércules se tornaron infranqueables para los griegos, y éstos, comenzando por Píndaro (OI. II, 44; Nem., III, 23) trazarían siniestros cuadros del Océano proceloso.

La expedición de Pytheas, mercader y astrónomo, contorneó la Península Ibérica, Francia y, verosímilmente, las Islas Británicas, descubriéndoselas a los helenos: desde ellas, al cabo de seis días, desembarcó en la misteriosa Thule (ilslandia? ¿la costa central de Noruega?, prosiguiendo su viaje a lo largo del litoral de Alemania, quizá hasta el Báltico o, con

4 Historia Natural, II, 169: trad. de García y Bellido, A., ed., La España en el siglo / de nuestra Era (Según P. Mela y C. Plinio). Buenos Aires, 1947, pág. 116 (Colec. Austral, 744).

5 En busca de las indias. Historia de los descubrimientos y exploraciones realizados desde la expedición al Pais de Punt, en 1493 antes de Jesucristo, hasta el descubrimiento del Cabo de Buena Esperanza en 1485. Trad. española. Barcelona 1971, pág. 26. Vid. asimismo ConTENAu, G., La civilisation phénicienne, n. éd. ref. París 1949, págs. 231-33, y Griaule, M., Les grands explorateurs, 2 éd. París 1948, págs. 12-19. Sobre Cerne, cf. Plinio, Hist. Nat., VI, 198199 (trad. cit., págs. 148-49).

${ }^{6}$ Cf. Schulten, A., Tartessos (2. ad. rev., Madrid, 1945), págs. 132-35, con los pasajes de las fuentes clásicas. 
cierta probabilidad hasta la desembocadura del Elba. Pytheas reveló, además, la configuración de nuestra Península e hizo observaciones sobre las mareas del Atlántico, el "pulmón marino" (¿Países Bajos?), noches de dos o tres horas, etc. Si no regresó por mar, la ruta escogida tuvo que ser la del ámbar (Rin-Mosela-Ródano) ${ }^{7}$.

Sin embargo, a efectos de las ideas, experiencias y supersticiones medievales en torno al Océano, la Antigüedad legó algunos mitos y leyendas sobre los archipiélagos del Atlántico que, unidos a otros ya cristianos, habían de coartar o estimular, según las circunstancias, esas navegaciones por el Mar Exterior.

\section{LAS ISLAS REALES E IMAGINARIAS DEL OCÉANO}

Como afirma C. Kappler, «la isla es, por naturaleza, un lugar en donde lo maravilloso existe por sí mismo fuera de las leyes naturales y bajo un régimen que les es propicio: es el lugar de lo arbitrario». Y, en orden a la geografía, añade: «Es probable que, además del placer de dar rienda suelta a la fantasía y del placer estético que pudieran procurar, las islas fuesen un expediente cómodo para imaginarse y situar, sin atormentar el espíritu, tierras desconocidas y esparcidas por el espacio marítimo" ${ }^{8}$.

Una especie de consentimiento universal hace del Poniente, en las riberas oceánicas, tanto el confín de los Bienaventurados o de la eterna primavera, como el vasto reino de los muertos. En la poesía griega estas representaciones emergen una y otra vez ${ }^{9}$. Solitarias 0 agrupadas en archipiélago, las islas que más impresionaron en la Antigüedad fueron las de clima subtropical, abundosas en prados y fuentes, en aves, canoras, etc., y cuyos habitantes vivían felices, merced a la generosa Naturaleza, sin mayor esfuerzo. Las Makárōn Nēsoi o Islas de los Bienaventurados, seducen asimismo a los geógrafos, viajeros y naturalistas del Imperio romano como Fortunatae Insulae.

Estrabón no dio crédito a Pytheas: vid., p. ej., I, 4, 5, y II, 4, 2, en: García y BelLido, A., España y los españoles hace dos mil años, según la "Geografia» de Strábon (Buenos Aires 1945), págs. 242 y 254-56 (Colec. Austral, 515). Sí, en cambio, Hiparco, Eratóstenes y Posidonio: cf. Schulten, A., ob. cit., págs. 151-52 y 194-95, pero, sobre todo, CarY, M.- Warmington, E. H., The Ancient Explorers. Londres 1932, págs. 33 y sgs. (Hay ed. rev., con bibliografía adicional. Baltimore 1963, «Penguin Books»).

- Monstruos, demonios y maravillas a fines de la Edad Media, trad. española. Madrid 1986, págs. 36-37. En general, vid. BABCOCK. W. H., Legendary Islands of the Atlantic. Nueva York, 1922 , págs. 34 y sgs.

9 Homero, Odisea, IV, 560-69; Hesíodo, Trabajos y días, 168-173 a; Píndaro, Olímpicas, II, 70-75, etc. 
Para Estrabón, «hállanse delante de la Maurousía (Marruecos), hacia los confines del Occidente ${ }^{10}$, no muy distantes del Atlas: son las Canarias o Madeira. Pomponio Mela también las sitúa allí: «Frente a él (Atlas), las Fortunatae Insulae, cuyo suelo produce espontáneamente una gran cantidad de frutos, que crecen sin cesar y sirven de alimento a sus tranquilos habitantes, más dichosos que los que viven en suntuosas ciudades...» ${ }^{11}$. Estas islas, según Plinio "el Viejo», están «a la izquierda de la Mauretania en la hora octava del sol» ${ }^{12}$. En consecuencia, los textos clásicos apuntan siempre a las Canarias, porque las islas Azores eran desconocidas, y las de Cabo Verde no podían cautivar a ningún marino, que a ellas arribase, por su aridez. Sobre la fabulosa Atlántida, insular o continental, no vamos a deternos aquí ${ }^{13}$.

Respecto a Madeira, los fenicios la descubrieron sin proponérselo, quizás, arrastrados por la corriente o una tempestad cuando bordeaban la costa de "Libia» (es decir, Marruecos), poco después de haber fundado Gades o Cádiz (1100 a. de J. C.) ${ }^{14}$. Al parecer, los etruscos trataron de colonizarla, pero los cartagineses se lo vedaron tras la batalla de Alalía (535 a. de J. C.). Se ha identificado a Madeira con las Purpurariae Insulae y con la lunonis Insula, dedicada por los púnicos a su diosa Tanit y que los romanos asimilaban a Juno ${ }^{15}$.

El archipiélago de los Azores, ignorado en la Antigüedad clásica - mas no por los Cartagineses, seguramente desviados de su ruta por vientos o corrientes adversos-, debe ser también mencionado: en la isla de Corvo, en 1749 , se hallaron monedas púbicas y cirenaicas, que el $P$. Enrique Flórez adquirió en Lisboa y, de allí, las llevó a Madrid; años más tardes, en 1761, tuvo a bien obsequiárselas al erudito sueco Johan Podolyn, quien publicó un artículo sobre las mismas. Basándose en R. Henning, autor de una monografía acerca de los cartagineses en las Azores, G. de Reparaz (hijo) la resume y concluye: «No queda más hipótesis verosímil que la de

10 Geografía, I, 1, 5 (trad. cit., págs. 322-24).

11 Corografía (o De situ Orbis), Il!, 102 (trad. cit. en la nota 4, pág. 41).

12 Hist. Nat., VI, 202 (trad. cit., págs. 150-52).

13 Cf. Shulten, A., Tartessoss, cap. X. Para este arqueólogo, la Atlántida de Platón (Timeo, 21 e -27 c, y Critias, 108 e - 120 d) es Tartessos: «Platón - dice - ha descrito la capital de la Atlántida y su comarca con arreglo a Tartessos, y al mismo tiempo ha proporcionado una imagen poética de la rica y próspera Tartessos, situada en la desembocadura del Guadalquivir" (págs. 177-78). Sobre las investigaciones posteriores, vid. Montenegro, A., Historia de España. Edad Antigua. I. España Perromana. Madrid 1972, págs. 248-60 y 268-300, más la bibliografía, págs. 593-600. Debe completarse con BLÁZQUEZ, J. M., Tartessos y los orígenes de la colonización fenicia en Occidente, 2a ed. ampliada. Salamanca 1975.

14 Cf. Diodoro, V., 19, 1-5.

15 Plinio, Hist. Nat., VI, 202-203 (trad. cit., págs. 150-51), 
una expedición de cartagineses, arrastrada contra su voluntad por algún temporal hasta aquellas lejanas tierras, y que a ellas hubiese abordado [la vasija con dichas monedas] fortuitamente hacia 330 a. de J. C.» ${ }^{16}$.

Por otra parte, la conciencia o premonición antiguas de que más allá de esas islas oceánicas había tierras aún incógnitas (Platón, Teopompo, Estrabón, Manilio, Séneca, etc.), se reforzaría con vestigios y tradiciones que los autores romanos consignan; entre ellos, Plinio «el Viejo» (Hist. Nat., II, 67), sobre los «indios» que el rey de los suevos donó, como esclavos, a $Q$. Metellus Celer, y que una tempestad había arrojado a las costas de Germanía, muy probablemente amerindios. A mediados del siglo XII y a comienzos del XVI, llegaron también a Europa embarcaciones del tipo kayak con supervivientes, como el de Ruán, en 1509; algunos de esos kayaks, arribados a Escocia, se conservan en los museos de Aberdeen y Edimburgo. ¿Eran, pues, esquimales o indígenas del Labrador, como ya Francisco López de Gómara sospechaba? ${ }^{17}$.

El eminente geógrafo español G. de Reparez (hijo) consideraba bastante normales los hechos anotados, por el juego de vientos y corrientes: "Las condiciones físicas del Atlántico favorecen -advierte-, al Sur del Estrecho de Gibraltar, la navegación hacia América, mientras que en la parte Norte del Oceáno corrientes y vientos ayudan la deriva hacia las costas británicas o europeas. Estos importantes factores físicos se han de tener muy en cuenta para el estudio de la posibilidad de los viajes involuntarios en una y otra dirección. $Y$ tales viajes, al llegar (como vemos que llegaron) a conocimiento de navegantes o de cronistas, como es lógico ejercieron la natural influencia en el concepto que los antiguos o los medievales se forjaban del mundo, haciéndoles suponer la existencia de tierras habitadas allende el Atlántico, fuesen o no las Indias» ${ }^{18}$.

Esa intuición, que no constancia manifiesta, de nuevas tierras en el

${ }^{16}$ La época de los grandes Descubrimientos españoles y portugueses. Barcelona 1931, pág. 29.

T Historia General de las Indias (Zaragoza 1552), en la «Biblioteca de Autores Españoles", ed. E. de Vedia (vol. XXII. Madrid 1852), pág. 165: "Si ya no fuesen de tierra del Labrador y los tuviesen por indianos...; ca también dicen cómo en tiempos del emperador Federico Barbarroja aportaron a Lubec ciertos indios en una canoa...». El cardenal Eneas Silvio Piccolomini (Pío II), en su Historia rerum ubique gestarum (o Cosmographia), se refiere a su vez al episodio de $Q$. Metelo Celer y el rey de los suevos, así como al de Lubeck según Otón de Freising, pero en relación con el Oceáno Índico: ex Oriente, no ex Occidente. Cf. KIMBLE, G. H. T., Geografphy in the Middle Ages. Londres 1938, pág. 213.

18 Ob. cit., pág. 38 . 
Océano situadas hacia el poniente, revistió en la Edad Media formas poético-religiosas y legendarias a tenor de la fe cristiana, pero condicionadas también, en parte al menos, por las tradicionales marineras del mundo Antiguo en su doble vertiente, positiva (Campos Elíseos, Islas de los Bienaventurados) y negativa (Tenebrosum mare). La memoria colectiva se reflejó en la cartografía, antes y después que ésta registrase las noticias, ya debidamente contrastadas por la experiencia, sobre el Atlántico Norte y la Europa Septentrional a partir del siglo IX; es decir, cuando las expediciones normandas abrieron perspectivas reales a la Geografía.

Durante la Ilamada «Edad Oscura», desde las inversiones germánicas a Carlomagno, y aún más tarde, en la Alta y Plena Edad Media (siglos IX-XIII), prevaleció la imagen de un Océano intimidatorio e inaccesible, heredada de la Antigüedad, salvo en el caso excepcional de los vikingos y su asentamiento en Islandia a fines del siglo IX. Tal prevención contra sus asechanzas mortales ocasionó un largo retraso pragmática y científicamente, en orden a los Descubrimientos, favoreciendo así toda la suerte de fábulas y consejas, no exentas, sin embargo, de encanto poético o de místico fervor. Es lo que sucede con la leyenda de San Brandán, el monje irlandés, el Purgatorio de San Patricio, la isla del Brasil y la de Antilia o de las Siete Ciudades, etc., que figuran en las cartas y planisferios hasta bien entrada la Edad Moderna ${ }^{19}$.

La rica tradición espiritual del mundo céltico tiene en las «navegaciones» un peculiar género literario («Llanura de la Alegría», "País de la Juventud», «Tierra de Promisión»...), cuya acción se desarrolla en el Océano o a sus orillas, evocando siempre aventuras y escenarios maravillosos, oníricos, cuando no de la vida sobrenatural, en el más allá ${ }^{20}$. Los viajes a islas remotas y fantasmagóricas, los imrama, son, acaso — con las visiones-, temas célticos por excelencia. Así la Navigatio Sancti Brendanni Abbatis, del siglo $x$, constituye en la versión que de la misma ofrece el arzobispo anglonormando Benedeit, a comienzos del siglo XII, una de las más bellas leyendas medievales ${ }^{21}$.

19 La de San Brandán aparece, por última vez, en el Atlas de Stieler, K. (Gotha, J. Perthes, 1867)

${ }_{20}$ Vid. BAR, F., Les routes de l'autre monde. Descentes aux Enfers et voyages dans l'audelà. París 1946, págs. 72-101, y $\mathrm{PATCH}, \mathrm{H}$. R., El otro mundo en la literatura medieval. Seguido de un "Apéndice": "La visión de trasmundo en las literaturas hispánicas," por M. R. LIDA DE MALKiEl. trad. española. México 1956, págs. 38-67.

21 Una excelente presentación y traducción es la de LEMARChand, Marie-José, El viaje de San Brandán, 2a ed. Madrid 1983, págs. XI-XXXVIII y 1-60. Vid. también SeverIN, T., "The Voyage of Brendan», en National Geographic, núm. 152-56 (1977), 769-97. 
El abad de Conflert, Brandán, se embarca con catorce monjes -instruido previamente por los ángeles- en un curragh irlandés, de cuero, y con víveres para cuarenta días. Arriban a una isla muy abrupta, donde visitan su castillo de mármol y cristal. Tras ciertas incidencias, recalan en otra isla poblada por enormes ovejas, y celebran la Pascua sobre un «islote» que se aleja bruscamente (era una ballena), pero sin perder el barco. Llegan después a una tierra donde se alza un gigantesco árbol de tronco blanco, rojo follaje y albos pájaros, uno de los cuales revela a Brandán que son ángeles caídos. La escala siguiente corresponde a la isla de Albea, con opulenta abadía y cuyos monjes gozan de bienandanzas tales como plena salud, alimentación providencialmente suministrada y hasta cirios que se encienden o apagan solos. De nuevo se hacen a la mar, ahora viscosa y terrible, con hambre y sed; pero inesperadamente sopla un viento bonancible que impulsa el curragh hasta una tierra que les provee de comida y bebida, ésta embriagante. Presencian la lucha entre dos monstruos. Enfilan hacia otra isla monástica habitada por niños, jóvenes y ancianos que salmodian y celebran, en coro, las horas canónicas: es una isla completamente llana, sobre la que se ciernen deslumbradoras nubes. Uno de los monjes, solicitado por la abadía, quédase allí. Como prueba para los incrédulos, Brandán parte con un cáliz. El viaje continúa en medio de sorpresas y azares: uvas como manzanas, peces descomunales, milagros diversos, capillas de oro y zafiro, encuentro con el Infierno conjurado por el signo de la Cruz, suplicio de Judas, isla escarpada del santo ermitaño Pol o Pablo que les augure el Paraíso, al cual llegan, por fin, tras cuarenta días de navegación: es el Jardín de las Delicias protegido por un alto muro y sobre un monte de gemas y metales preciosos. Los monjes contemplan desde lejos tan arrebatador espectáculo, mientras la música celestial inunda suavísimamente sus oídos. El mensajero divino que los acoge, al reembarcarse Brandán con sus monjes, les bendice. Al cabo de tres meses retornan a Irlanda y narran su prodigioso viaje atlántico, en medio del júbilo, piadoso, de todos ${ }^{22}$.

Ahora bien, ¿qué sentido tiene este imram insólito? Las interpretaciones "geográficas» e «históricas" que se han propuesto, adolecen en general de premisas falsas, o son, en todo caso, arbitrarias. Olvídase que se trata de un tema literario, «iniciático» por su inspiración y su contenido. Verdad

22 Hay múltiples versiones, según las cuales duró la aventura cuarenta días o siete años... El cómputo, mágico-religioso, es aquí el del tiempo mítico: cf. al respecto ELIADE, M., Lo sagrado y lo profano, trad. españ., Madrid 1967, págs. 70-113. En cuanto a las influencias que se han observado, de otras literaturas, la árabe (Sindbad el Marino) parece figurar entre las más probables. 
es que en el globo de Martin Behaim se ilustra la isla con una sumaria referencia a un hecho supuestamente «real»: «En el año 565 de J. C. - leemos-, San Brandán arribó con su nave a esta isla, donde vio muchas maravillas y, transcurridos siete años, regresó a su país» ${ }^{23}$. Los cartógrafos, desde el siglo xIII (planisferio de Hereford) consideraban, ya «las islas» o archipiélagos de San Brandán (Cenarias, Madeira, quizá también las Azores), ya «la isla» del valeroso abad, como en el globo aludido y, por lo común, en el Atlántico Norte. De lo que no cabe duda es de la popularidad que rodeó a esta leyenda desde la emigración céltica al Continente europeo, tras las invasiones germánicas del siglo $\mathrm{v}$; tanto, que a fines del siglo XVI un hijo de Sebastián Cabot aceptaba su existencia sin discusión ${ }^{24}$. Por lo demás, no fue un incentivo poderoso en la génesis del Descubrimiento de América.

Sin embargo, según $R$. Thévenin «el encuentro con algún gigantesco cetáceo polar» prueba que «San Brandán se adentró mucho en los mares del Norte, bastante más allá del círculo ártico, hasta los grados 72 ó 73, y que descubrió, casi con seguridad, la isla Jan Mayen en el momento de la erupción. La descripción que nos ha dejado corresponde a la realidad» ${ }^{25}$. En cuanto a su segundo viaje, los datos sobre el tipo de embarcación coinciden con los del gran umiak esquimal, a bordo del cual podía haber llegado a Canarias o, en todo caso, a Madeira ${ }^{26}$.

Otra isla legendaria era «Brasil», nombre que sustituiría al de Santa Cruz, dado por Pedro Alvares Cabral al territorio occidental del Atlántico Sur (actual Estado de Bahía), en 1500. Se consigna por vez primera en la carta de Dulcert (1339) y, casi dos siglos y medio después, figura todavía en el planisferio de Mercator (1595). Ya se la situaba entre las Azores, ya - de forma circular - al O de Irlanda, o en ambos puntos a la vez. El origen de la boga que alcanzó la supuesta isla se ha explicado a partir de Marco Polo, quien menciona una planta con ese nombre, cultivada en Sumatra, el «palo brasil» o rojo, pero también de una isla encantada y paradisiaca, así denominada en lengua céltica ${ }^{27}$. A fines del siglo XV zarparon, incluso, de Bristol cuatro naves en busca de tal isla y de la de las «Siete Ciudades» o «Antilia».

23 Cf. Gaffarel, P., Histoire de la Découverte de l'Amérique, depuis les origines jusqu'à la morte de Christophe Colomb, vol. I. Paris 1892, pág. 210.

${ }^{24}$ Cf. Albuquerque, L. de, Introduçāo à História dos Descobrimentos portugueses. Coimbra 1962 , pág. 154.

25 Les pays légendaires devant la science (cf. nota 3), pág. 62.

26 Thévenin, R., ob. cit, ibidem.

27 Albuquerque, L. de, ob. cit., págs. 154-55, nota 139 
Ésta, que se localizaba al O del Atlántico Norte, según la leyenda fue poblada por siete obispos y sus respectivos fieles procedentes de la orla atlántica peninsular - que huían de la invasión musulmana-, hacia el año 734. También aquí resuena el eco de los textos clásicos, sobre la provincia Naturaleza y el gozo de sus moradores. Como en el caso de San Brandán, «antilia» preocupó ciertamente a los cartógrafos y navegantes: en el globo de Martín Behaim se da la fecha 741 y se menciona al arzobispo de Porto. Es más: el P. Las Casas y António Galvāo difundirían la especie de que "Antilia» fue «redescubierta» por los portugueses en tiempo de D. Enrique El Navegante, conseja totalmente fantástica ${ }^{28}$. Pero, sin duda, no faltaron los intentos de llegar a la isla de las Siete Ciudades: Alfonso V de Portugal le incluyó en la donación que hizo a Fernão Teles (1475), y Juan II en el plan expedicionario de Fernāo Dulmo (1846).

\section{POESIAA E HISTORIA DE LAS EMPRESAS ATLÁNTICAS NORMANDAS}

La gran expansión escandinava del siglo IX, que inició el movimiento migratorio y depredador de esos pueblos nórdicos hasta la constitución de núcleos políticos estables en las estepas rusas, el mar Báltico, el del Norte, el Continente europeo (Normandía) y el Mediterráneo, tuvo dos vías liberadoras: la del C (à vestrvegum í víkingu, "sobre la ruta de Occidente en expedición vikinga", como rezan los textos rúnicos y cantas las "sagas») y la del E (í austrvegi) o de los varegos, oriundos de Suecia, con centro en Kiev y relaciones bélico-mercantiles con Tsargrad (Constantinopla).

La ruta del $O$ puede seguirse, en sus diversos tramos y etapas, acudiendo a la tradición literaria fijada por escrito desde comienzos del siglo XII hasta fines del XIV: el Islendingabók, el Landnámabók, la Groenlendinga Saga y la Eiriks Saga Rauda ${ }^{29}$.

28 Vid. las referencias dadas en ob. cit., pág. 156, notas 141-44. Otros relatos sobre islas y viajes hacia el Poniente, en el Atlántico Norte, circularon durante el siglo xVI, atribuyéndose al XIV: así, p. ej., en 1558 se hablaba de una epístola del veneciano Antonio Zeno, contando un viaje, en 1380, a cierta isla "Frisland" en compañía de su hermano Nicolò, con el que navegó luego rumbo a "Estotiland". EI relato ha sido rechazado por la crítica histórica como puramente imaginario, aunque A. E. Nordenskiöld se iniclinaba a aceptar su veracidad: cf. THÉVENIN, R., ob. cit., págs. 64-69.

29 Para la historia de las expediciones normandas, cf. Musset, L., Las invasiones. El segundo asalto a la Europa cristiana (Siglos vil-xi), trad. española. Barcelona 1968, págs. 59-94, 183204 y, sobre las fuentes y bibliografía, págs. 218-22 y 229-38. Una clara y documentada síntesis es también la de Durand, F., Les Vikings, 3e éd. mise à jour. París 1977, págs. 21-79. Más información suministra el vol. xvı de los "Atti delle Settimane di Studio" de Spoleto: I Normanni 
Según viejos relatos (DicuIL, 825), Islandia fue descubierta (ca. 785) por unos monjes irlandeses (papar, en nórdico); pero, al llegar los noruegos, (ca. 870) aquellos primeros cristianos se marcharon "porque no estaban dispuestos a vivir en compañía de paganos" y "dejaron tras sí libros, campanillas y báculos, por los cuales se podía comprobar que eran irlandeses». En torno al año 930 , la isla hallábase ya poblada y organizada políticamente como una federación. Entre tanto, la antigua Thule había cambiado de nombre, siendo ahora Island o «Tierra del hielo". Un noruego arrastrado por vientos contrarios, hacia el $\mathrm{O}$, vio unos arrecifes a los que dio su nombre: Gunnbjornarsker. El hecho se sitúa en 920, pero ya antes esa tierra había sido elogiada por el pirata Naddod, quien fue en realidad su descubridor y quien la denominó Snaeland («País de la Nieve»). Convencido de que era necesario colonizarla, el jarl Erik «el Rojo", hijo de Thorvald, partió en el año 986 y la ocupó dándole el nombre de Groenlad («Tierra Verde»), "alegando que, si tenía un nombre atractivo, los hombres se sentirían inclinados a ir allí». Encontró vestigios materiales que probaban estar ya habitada (viviendas, restos de embarcaciones, utensilios de piedra, etc.). Quince años después, el rey Olaf Tryggvason introduciría el Cristianismo en Noruega e Islandia. El asentamiento nórdico en el SO de Groenlandia, que proporcionó a los colonos abundate pesca y ganado, se mantuvo a un nivel relativamente cómodo hasta mediados del siglo XIV; es decir, cuando se recrudecieron el frío y los ataques de los skraelings o esquimales (?), factores adversos que, unidos a la interrupción de las comunicaciones con la metrópoli, aceleraron su ruina.

Durante ese épico siglo x los vikingos de Groenlandia no se recluyeron en ella, sino que, impulsados por su marinero dinamismo y su ansia de aventuras, pusieron rumbo, a bordo de aquellos veloces kenningar («corceles de las olas»), hacia nuevas tierras occidentales. La Groenlendinga Sega nos narra, a fines del siglo XIV pero sobre la base de una fidedigna tradición oral y escrita, cómo Bjarni Herjolfsson navegó durante varios días, al SO de Groenlandia, avistando tierras bajas y boscosas, en las que no desembarcaron. Fue el hijo de Erik «el Rojo», Leif Eirksson, quien

e la loro espansione in Europa nell'Alto Medioevo. Spoleto 1969. Los textos nórdicos más accesibles se encuentran en: JONES, G. , El primer Descubrimiento de América (Establecimiento de los Vikingos en Islandia, Groenlandia y América), trad. española. Barcelona 1985, págs. 119205, y en La Saga de los Groenlandeses y la Sala de Eirik el Rojo. Trad., prólogo y notas de A. y P. Casariego Córdoba. Madrid 1986 (especialmente págs. 1-31, 50-55 y 61-66, con las notas, págs. 79-113). Sobre el knorr vikingo ilustra LANDSTRÖM, B., El buque. Historia del buque, desde la balsa primitiva hasta el submarino atómico. Trad. española. 3. ed. Barcelona 1983, págs. 5865. 
hacia el año 1000 descubrió un país donde crecían silvestres el trigo y la vid, pero en el que no permaneció. Cuatro años después, sin embargo, tres drakkars con una tripulación de 140 hombres se hizo a la mar bajo el mando de Trhobjarni, Snorri Thorbrandson y Thorfinn Karlsefni, el más respetado de los tres. Zarparon de Vestribygdh, actual Godthaab, en Groenlandia. Leif había dado nombres a las tierras visitadas por él: Helluland («Tierra de las Rocas»), Markland («Tierra de Bosques») y Vinlad («Tierra de la Vid»). Refiere la saga que allí, en Vinland, se criaba un espléndido salmón, que el ganado no necesitaría de pienso en ella para el invierno, que no heló ni se marchitó la hierba, que el día y la noche «tenían una extensión más próxima que en Groenlandia y en Islandia»... «Pernoctaron y luego, por la mañana — prosigue el relato- Leif anunció a la tripulación: "Tenemos dos tareas que hacer ahora, y en días alternos tenemos que recoger uvas o cortar cepos y talar madera, para aprovisionar mi nave con tales cosas". Actuaron según estas órdenes y se dice que llenaron de uvas (ipasas?) el bote de remolque. Se consiguió un cargamento que Ilenaba la nave y a la primavera terminaron los preparativos, y partieron. Leif dio al territorio un nombre de acuerdo con cuanto de bueno había visto, llamándolo Vinland.... ${ }^{30}$.

La investigación moderna ha identificado Helluland, el País Rocoso y de los zorros azules, con el extremo más oriental del Labrador; Markland, con Terranova, por donde Thorfinn Karlsefni y sus guerreros flanquearon una isla "de las corrientes" (¿Anticosti, en medio del golfo del río San Lorenzo? ¿La isla del cabo Bretón?); y Vinland, con Nueva Escocia. Aquí, los indígenas (skraelings) parecen ser 0 algonquinos 0 , más probablemente, esquimales, de los que aquellos vikingos nos han conservado algunos vocablos.

El Viaje de Karlsefni a Vinlandia (parte del Hauksbók) nos ha transmitido el nombre de aquellos parajes: Furdustrandir o «Playas Maravillosas», que se han relacionado con la costa SE del Labrador, Nueva Escocia e incluso la Nueva Inglaterra (¿Massachusetts?). No obstante, las huellas de materiales faltan o, si se han invocado, trátase de mixtificaciones. En cuanto a la vid silvestre, explícase, quiza, por un optimun climático, ya que no se da actualmente en esas latitudes. Groenlandia ofrece, por el contrario, importantes silos arqueológicos entre Godthaab y el cabo Farewell, con una diócesis - desde el año 1000 - en Gardar. Se han hallado osamentas

30 Cf. JONES, G., ob. cit., pág. 168; también La Saga de los Groenlandeses..., ed. cit., págs. $8-11,22-26$ y $61-73$. 
de bueyes, caballos, ovejas y cabras. Cuando Colón arribó al islote de Watling -tradicionalmente, a Guanahani-, hacía unos ochenta años que ningún navegante abordaba a Groenlandia, cuya decadencia y oscuro final sobrevinieron en torno a $1400^{31}$.

Las expediciones normandas suscitaron desde muy temprano la curiosidad geográfica en el Occidente europeo. Así, el culto rey sajón Alfredo «el Grande» - que tradujo y revisó los Historiarum adversus paganos libri septem, de Paulo Orosio-, a fines del siglo Ix tuvo conocimiento de Germania, los países bálticos y la Europa septentrional, a través de Ottar el Normando y Wulfstan el Anglo, quienes habían llegado hasta Arkángelsk y el golfo de Gdánsk ${ }^{32}$. Adam de Bremen (ca. 1070) supo también de las navegaciones vikingas, como lo acredita su Historia del arzobispado de Hamburgo. Más tarde, hacia 1425, el cartógrafo danés Claudius Clavus influiría en la génesis de los descubrimientos portugueses, pues D. Enrique «el Navegante» conoció su mapa de Escandinavia -seguramente diseñado en Venecia-, con ocasión del viaje de su hermano D. Pedro (1428). Ese mapa se perdió, aunque existe una copia del mismo en Nancy. Pudo haber animado a D. Enrique y al rey Alfonso $V$, entre otros incentivos, a buscar «islas y tierra firme» en el Atlántico Occidental. El monarca portugués mantenía estrecho contacto, hacia el año 1470, con el danés Cristián I para descubrir algún paso en el NO, acaso pensando en las Indias Orientales, a tenor de la epístola toscanelliana y del mapa adjunto (1474) sobre el Océano que, según los cálculos de Marino de Tiro, separaba a Europa de Asia, Johannes Scoluus (Skolp), un piloto de incierta nacionalidad (danés, noruego o alemán) al servicio de Cristián I, figura en los documentos y crónicas de los siglos XVI-XVII como descubridor del Labrador (1476); pero Gaspar Frutuoso (ca. 1580/91) afirma que fue Joāo Vaz Corte-Real quien llegó hasta la nueva tierra de Bacalhaos (Labrador). En este caso pudo tratarse de una sola expedición patrocinada por Alfon-

31 Cf. JONES, G., ob. cit., págs. 72-93.

32 Magnusson, M., Vikings! (Nueva York 1980), págs. 57-59, se ocupa de Ottar, el noruego acogido a la corte de Alfredo de Wessex, quien supo de Skiringssal, un activo puerto comercial al SO de la actual Oslo y que se ha identificado con Kaupang. Ottar (Ohthere, en inglés antiguo) le dio mucha información sobre Escandinavia. Vid. también acerca de este viajero y Wulfstan, WHITELOCK, D., The Beginnings of English Society. Harmondsworth 1952, págs. 12-13, 59 y 123 (A Penguin Book, A245).

33 Cf. Refaraz, G. de (hijo), La época de los grandes descubrimientos españoles y portugueses (cit. en la nota 16), págs. 130-32. Por su parte, CoRTesão, J., desarrolló el tema «A viagem de Diogo de Teive e Pero Vasquez de la Frontera ao Banco de Terranova em 1452", en el curso 1932-33 de la Universidad de Sevilla: el primero era escudero del Infante D. Henrique, y el segundo un piloto andaluz. Vid. un resumen en "Archivo Histórico de Marinha", N. ${ }^{\circ}$, 1933, 
so $V$ (1472), que no deparó información útil debido a la intrínseca dificultad geográfica de la empresa ${ }^{33}$.

y sus observaciones en Teoria geral dos Descobrimentos portugueses. Lisboa 1984, págs. 32 36 ("Obras Completas», 29).- Sobre Claudius Clavus, además de Kretschmer, K., Historia de la Geografía, trad. española 2. a ed. Barcelona 1930, págs. 124, cf. PINHEIRO MARQuÉs, A., Origem e desenvolvimento de Cartografia portuguesa na época dos Descobrimentos. Lisboa 1987, págs. 52 y 201-3. - Como síntesis más reciente sobre la historia del Océano Atlántico, es notable el ponderado libro de CéSPEDES del CASTILLO, G., La exploración del Atlántico. Madrid 1991; véanse especialmente las págs. 11-105. 